Vol. 6(2), pp. 18-26, March 2014

DOI: $10.5897 / J$ EIR2014.0353

Artic le Number. 2BE3B1446993

ISSN 2006-9790

Journal of Engineering and Technology

Copyright $\odot 2014$

Research

Author(s) retain the copyright of this artic le

http://www.academicjoumals.org/J EIR

\title{
Effect of Argon plasma and ion beam on the morphology and wettability of polyethylene terephthalate (PET)
}

\author{
A. Atta ${ }^{1}$, A. M. Abdel Reheem ${ }^{2}$ and M. M. Abdel Rahman ${ }^{2 *}$ \\ ${ }^{1}$ Physics Department, National Center for Radiation Research and Technology (NCRRT), Atomic Energy Authority \\ (AEA), Cairo Egypt. \\ ${ }^{2}$ Accelerators and Ion Sources Department, Nuclear Research Center, Atomic Energy Authority, P. O. Box 13759 \\ Inchas, Cairo, Egypt.
}

Received 27 January, 2014: Accepted 6 March, 2014

\begin{abstract}
Plasma and ion beams are considered tools that can improve existing materials or create new materials. Their technology is widely used to alter the surface properties of polymers without affecting their bulk properties. The treated polymers have found various applications in microelectronics, biomedical and chemical industries. In this work, the use of Argon plasma and Argon ions produced from cold cathode ion source as a method for the morphology and wettability of Semi crystalline polyethylene terephtalate (PET) foils are investigated. A cold cathode ion source was used as a preparation tool of the surface of polyethylene terephthalate PET polymer substrate to be ready for various applications as coating or thin film deposition. Argon ions of $1.5 \mathrm{keV}$ are produced from the cold cathode ion source with an operating gas pressure of $2 \times 10^{-4} \mathrm{mbar}$. The induced effects in the structure, surface morphology, and surface wettability were investigated by means of the Fourier transform infrared spectroscopy (FTIR), scanning electron microscope (SEM) and by the contact angle methods, respectively. The change in the contact angle on PET as a function of Argon plasma time and ion beam fluence was also studied. Changes in surface free energy of polymer surface after Argon plasma irradiation were observed.
\end{abstract}

Key words: Cold cathode ion source, Argon plasma and ion beams, polyethylene terephthalate (PET) foils.

\section{INTRODUCTION}

Polymer materials with improved mechanical, optical or electrical properties have been widely used in a variety of industrial applications. However, their use is sometimes limited by undesired properties of the surface, contrary to very useful characteristics of the bulk, such as low weight, chemical inertness and high impact resistance. Therefore, it is interesting to modify the surface in a controlled manner to enhance wettability, printability, adhesion with other materials or with biological components, compatibility (as in the production of

*Corresponding author. E-mail: moustafa82003@yahoo.com.

Author(s) a gree that this a rticle remain permanently open access under the terms of the Creative Commons Attribution License 4.0 Intemational Lic ense 
material blends using two immiscible polymers), etc. (Cho et al., 2003; Ektessabi and Sano, 2000; Spohr, 1990; Ektessabi and Yamaguchi, 2000). Plasma treatment does not produce toxic waste in contrast to the treatments using chemicals. The plasma is capable to exert four major effects (Chen, 2001; Reznickova et al., 2011) surface cleaning, surface ablation or etching, surface cross-linking, and modification of the surface chemical structure, occurring both in situ or after subsequent exposure to the atmosphere. These effects depend on a presence of the active species in plasma (electrons, ions, radicals, photons) which interact with polymer surfaces and modify their chemical and physical properties. Ion irradiation is an established tool for modifying the chemical structure and physical properties of the polymers Pelagad et al, 1980; Chico et al., 2012). The ion beam irradiation technique has proven more effective in modifying polymer than other particle beam irradiation techniques because of its higher cross section for ionization and larger linear energy transfer (Drabik et al., 2007). Our aim of this work was intended to use plasma and ion beam currents produced from cold cathode ion source as a method for the morphology and wettability of semi crystalline poly ethylene terephtalate (PET) foils are treated and investigated.

\section{EXPERIMENTAL OUTLINES}

A schematic diagram of the cold cathode ion source and its associated electrical circuit is shown in Figure 1. It consists essentially of stainless steel anode cylinder with $30 \mathrm{~mm}$ length and $22 \mathrm{~mm}$ diameter connected with positive voltage power supply of $+10 \mathrm{kV}$, cathode disc of diameter $22 \mathrm{~mm}$ and $2 \mathrm{~mm}$ thickness, and a semitransparent $50 \%$ as exit aperture. The extractor electrode connected to negative voltage power supply, Faraday cup placed at $30 \mathrm{~mm}$ distance from an exit aperture. PET sample put on faraday cup at distance $3 \mathrm{~cm}$ from the cylindrical cathode. A PET samples are immersed in acetone liquid and put it in ultrasonic apparatus to clean it. Cold cathode ion source was used to obtain the Argon plasma and ion beam and consequently irradiation PET surface using Argon plasma and ions. PET is polyester having a high melting point due to the presence of aromatic ring and has a very good mechanical strength. It is semi-crystalline in nature and is resistant to heat and moisture and virtually unattached by many chemicals. It has extensive use in textile fibers.

The working gas is admitted to the ion source through a hose fixed in a Perspex flange at the upper side of the anode. A complete vacuum system is used to evacuate the ion source chamber. It consists of stainless steel mercury diffusion pump of speed $270 \mathrm{l} / \mathrm{s}$ provided with electrical heater and backed by 450 $\mathrm{l} / \mathrm{min}$ rotary fore-line vacuum pump. The rotary pump is used to evacuate the system to pressure of $10^{-2}$ to $10^{-3} \mathrm{mbar}$, while the mercury oil diffusion pump is used to evacuate the ion source vacuum chamber to the order of $10^{-5} \mathrm{mbar}$. A liquid nitrogen trap is fixed between the ion source chamber and the mercury oil diffusion pump in order to prevent the mercury vapor from entering the ion source chamber. The working gas is transmitted to the ion source from a gas cylinder through a needle valve to regulate the rate of gas flow. The plasma generation for this ion source is based on the ionization mechanism produced by primary electrons colliding with gas molecules due to a potential difference between the anode and the cathode. Therefore, high output ion beam current can be extracted axially in a direction normal to the discharge region. The anode is made of stainless steel material which is featured by high ionization coefficient and it is cylinder to improve the stability of the discharge. PET samples were put on Faraday cup at distance $3 \mathrm{~cm}$ from the anticathode. A PET samples are immersed in acetone liquid and put it in ultrasonic apparatus to clean it. Cold cathode ion source was used to obtain the plasma and Argon ion beams and consequently irradiation PET surface using plasma and Argon ions. PET is polyester having a high melting point due to the presence of aromatic ring and has a very good mechanical strength (Soliman et al., 2013). It is semi-crystalline in nature and is resistant to heat and moisture and virtually unattached by many chemicals. It has extensive use in textile fibers.

\section{RESULTS AND DISCUSSION}

In this study, the system is evacuated to about $3 \times 10^{-5}$ mbar to remove the residual gases before the Argon gas injection in the ion source. The ion source apparatus was cleaned before introducing inside the vacuum system. It was polished, and washed by acetone. The polishing of the electrode parts should remove the irregular parts from their surfaces and the contamination due to the erode materials of the discharge. The plasma and the extracted Argon ion beam from the cold cathode ion source were used to irradiate Polyethylene terephthalate (PET). The sample considered in our investigations was PET (polyethylene terephthalate), provided by Goodfellow Company. The polymer samples, $50 \mu \mathrm{m}$ thickness foils, were cut into $10 \times 10 \mathrm{~mm}$ pieces, ultrasonically cleaned in alcohol to remove organic material and dried with hot air before treatment. The PET films are exposed to Argon plasma exposure process. We use plasma technique "reactive ion etching (RIE) system" with the Argon plasma parameters are the working pressure is $2 \times 10^{-4}$ mbar and discharge voltage 900 volte, $g=180$ gauss varied time exposure from 0 to $4 \mathrm{~min}$ and Argon ion beam for 0 to $4 \mathrm{~h}$.

In the present work, discharge and output characteristics of this ion source using Argon plasma and Argon ion beams were done and this type of ion sources was used as a preparation tool of the surface of PET polymer substrate to be ready for coating or thin film deposition. Modifications in optical and surface properties of PET polymer induced by Ar plasma and Ar ion beam irradiation have been investigated in Atomic Energy Authority - Egypt), by:

1) FTIR spectra of the pristine and the irradiated samples were investigated using (FTIR-Beckman-4250) spectrophotometer in the range $400 \mathrm{~cm}^{-1}$ to $4000 \mathrm{~cm}^{-1}$ at National Center for Radiation Research and Technology (NCRRT), AEA, Cairo, Egypt. The irradiated PET films were exposed to atmosphere for a few days before the FTIR experiments were conducted.

2) SEM (Model, JEOL, Japan) at NCRRT, AEA, Cairo, Egypt, was used to investigate the surface morphology of the pristine and PET surfaces after bombarded by Argon plasma and Argon ion beam. 


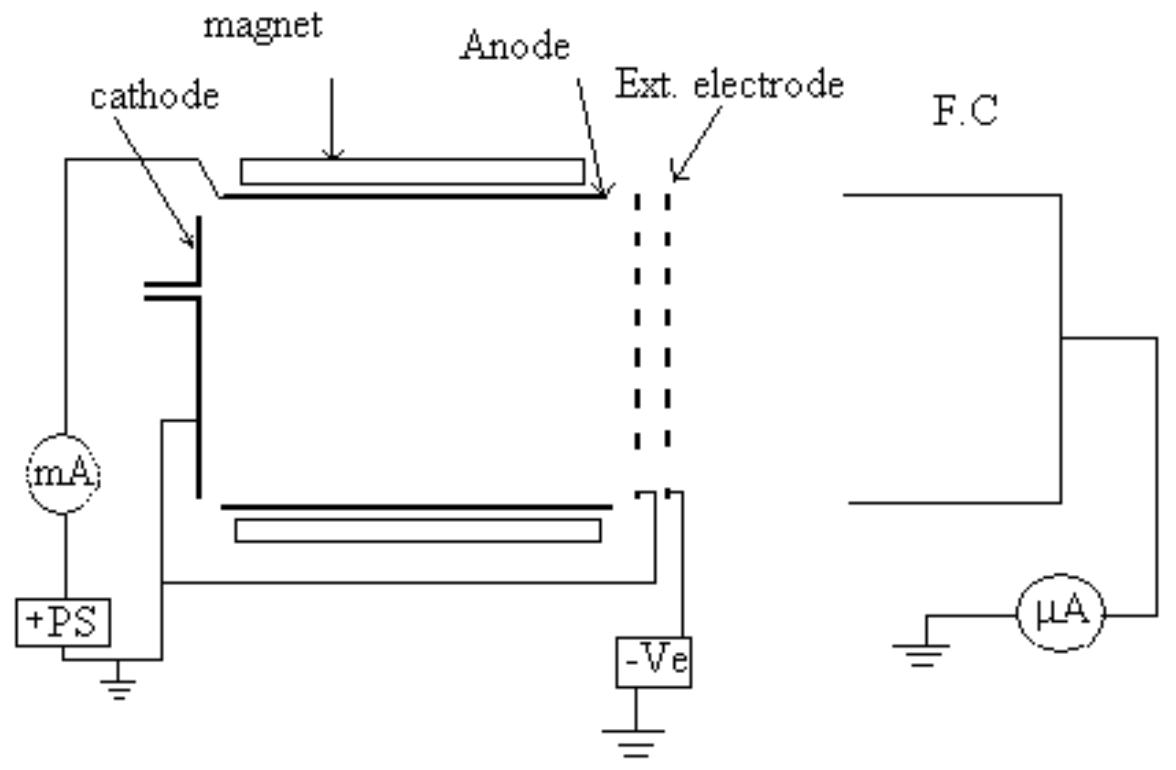

Figure 1. Experimental arrangement for irradiation of polymer samples using Ar plasma and $\mathrm{Ar}$ ion beam.

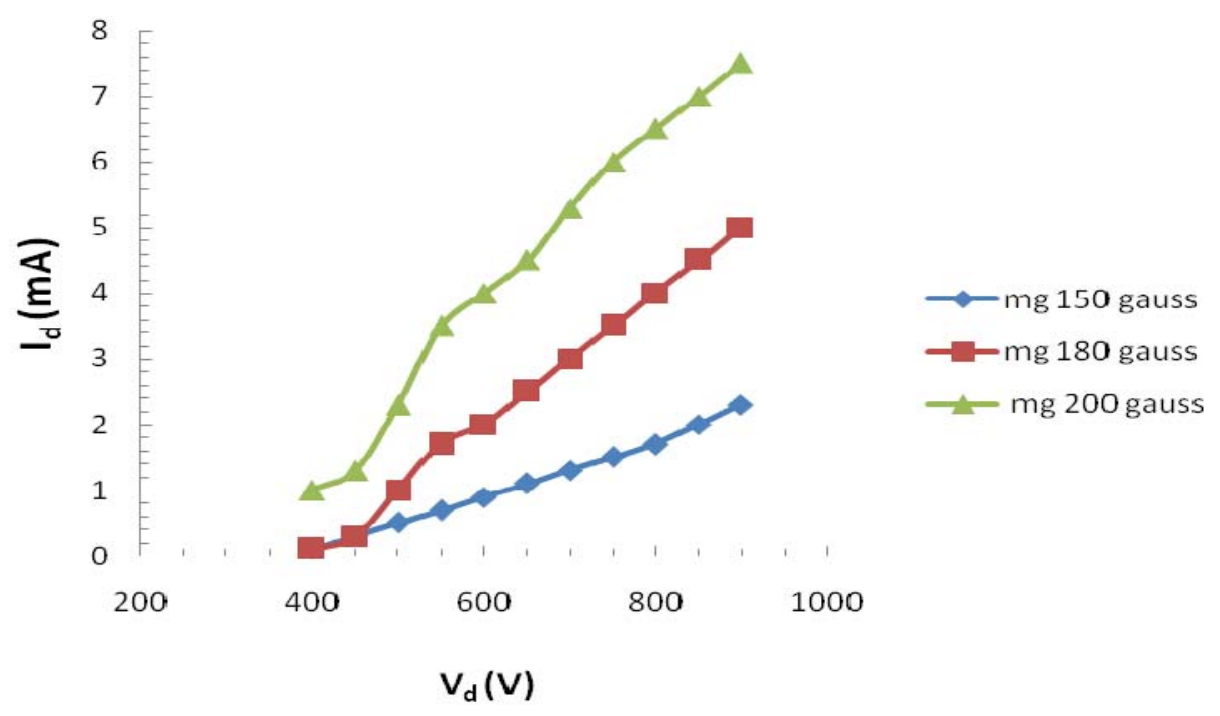

Figure 2. The relation between the electrical discharge current and the electrical discharge voltage with different magnetic field intensities.

3) The contact angle in a sessile drop method was measured by a contact angle meter (Cam Micro, Tantec). Each value of the contact angles was taken as an average from the five different samples fabricated under the same modification conditions. Surface free energy, that is, the sum of the polar force and the dispersion force, was calculated by measuring the contact angles of three different polar liquids (water and diiodomethane). From the measured contact angles, the polar forces and the dispersion forces were calculated using the Owen method (Soliman et al., 2013).

\section{Ion source characteristics}

Figure 2 shows the relation between the electrical discharge current, $I_{d}$, and the electrical discharge voltage, $V_{d}$, at pressures $P=2 \times 10^{-4}$ mbar using Argon gas. It is clear that by increasing the discharge voltage, the discharge current increases at different magnetic field 


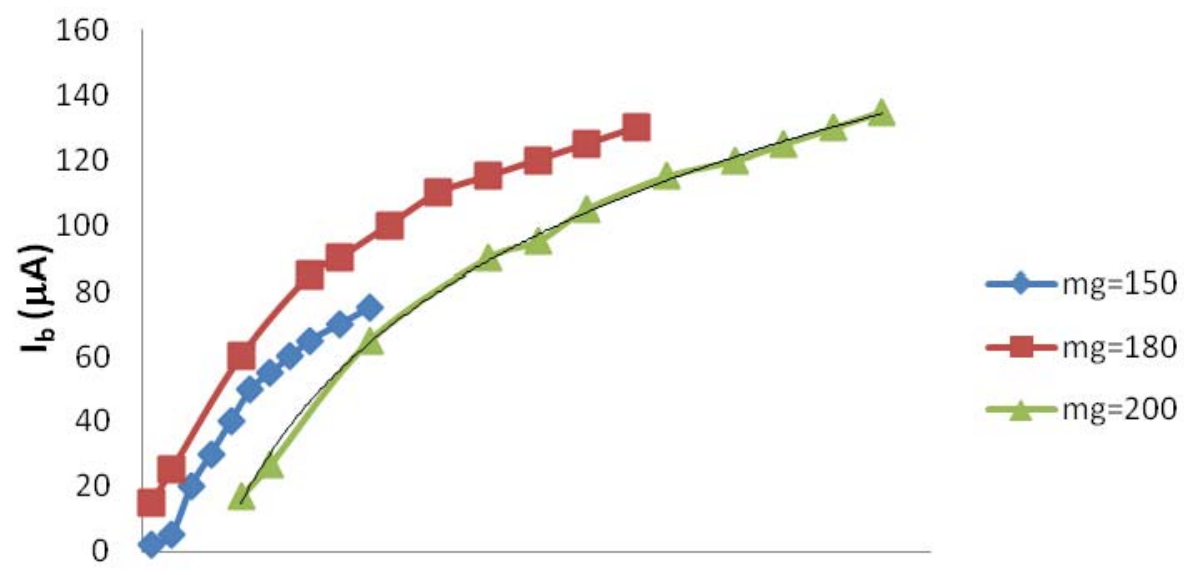

$\begin{array}{lllllllllllllllll}0 & 0.5 & 1 & 1.5 & 2 & 2.5 & 3 & 3.5 & 4 & 4.5 & 5 & 5.5 & 6 & 6.5 & 7 & 7.5 & 8\end{array}$

$I_{d}(m A)$

Figure 3. The relation between the electrical discharge current and the output ion beam current, with different magnetic field intensities.

intensities where the characteristic of such discharge is characterized by abnormal glow (Abdelrahman et al., 2008). This magnetic field is created an electromagnet coil wrapped around the cylindrical anode. Whereas, this magnetic field provides an increase of electron trajectories, hence, increasing the electron path which enhances the probability of ionization and then increase the discharge current. It was also found that an increase in magnetic field intensity was accompanied by an increase in the discharge current. This increase may be due to an increase in magnetic field vector parallel anode surface, and this leads to minimization in electron current in the anode region (Kotov 2004).

Figure 3 shows the relation between the electrical discharge current, $I_{d}$ and the output ion beam current, $I_{b}$ at 150,180 and 200 gauss magnetic field intensities without extraction voltage. It could be seen that from this figure, maximum output ion beam current was obtained at magnetic field intensity of 180 gauss.

Figure 4 shows the relation between the electrical discharge current, $I_{d}$ and the output ion beam current, $I_{b}$ at 180 gauss magnetic field intensity with extraction voltage $V_{\text {ext }}=-600 \mathrm{~V}$. It could be found from this figure that, an increase of the discharge current was accompanied by an increase of the output ion beam current at magnetic field intensity of 180 gauss and Argon gas pressure, $\mathrm{P}_{\mathrm{Ar}}=2 \times 10^{-4}$ mbar.

\section{Plasma and ion beam irradiation of polymers}

The irradiation of all the polymer samples used in the present study were carried out by locally designed, a modified saddle field ion source at Egyptian Atomic Energy Authority, Egypt. The Ar ion beam irradiation was carried out in a vacuum chamber of $10^{-5} \mathrm{mbar}$, using a modified saddle field ion source. The ion fluence was estimated by time of irradiation and beam current as (Soliman et al., 2013):

$$
I=Q / t=D q e / t=\phi \text { Aqe } / t
$$

Where I ion current $(A), Q$ total charge, $D$ : dose (ion fluence in ions $/ \mathrm{cm}^{2} \times$ area $(A)$ of irradiation in $\mathrm{cm}^{2}$. and $\mathrm{q}$ is the charge state, e electron charge $\left(1.6 \times 10^{-19} \mathrm{C}\right)$, finally $\mathrm{t}$ is the irradiation time in seconds.

\section{FTIR spectral studies}

FTIR spectroscopy has been found to be an important technique to understand the changes in the molecular bonds after irradiation. The changes have been observed from the relative increase or decrease in the intensity of the typical bands associated to the functional group present in the polymers. FTIR spectrum of pristine, Argon plasma and Argon ion beam irradiated PET are shown in Figure 5. By bombardment, the PET polymers by Argon plasma and ion beam were observed to decrease in the band intensities. It might be ascribed to the possible transient recrystallization due to Argon plasma and ion beam effect. The reduction in the intensity of the typical bands indicates some degradation of PET polymer by plasma and ion beam (Zhiyong et al., 2009). The infrared absorption spectra of the PET substrates in a wave number range of 2000 to $4000 \mathrm{~cm}^{-1}$ reveal the presence of an absorbance band at about case of Argon plasma than Argon ion beam. 


$$
\begin{gathered}
\mathrm{V}_{\mathrm{d}}=900 \mathrm{~V}, \mathrm{~V}_{\text {ext }}=-600 \mathrm{~V}, \mathrm{p}=2 \times 10^{-4} \text { mbar, } \mathrm{g}=180 \\
\text { gauss }
\end{gathered}
$$

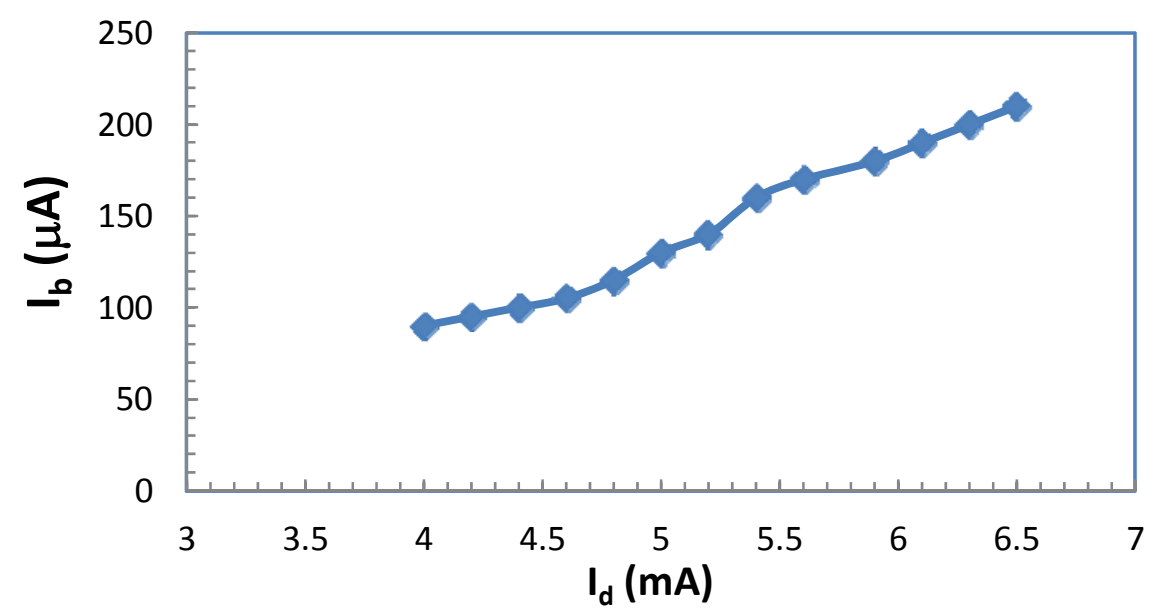

Figure 4. Output ion beam current versus discharge current using Argon gas at $P=$ $2 \times 10^{-4} \mathrm{mbar}$.

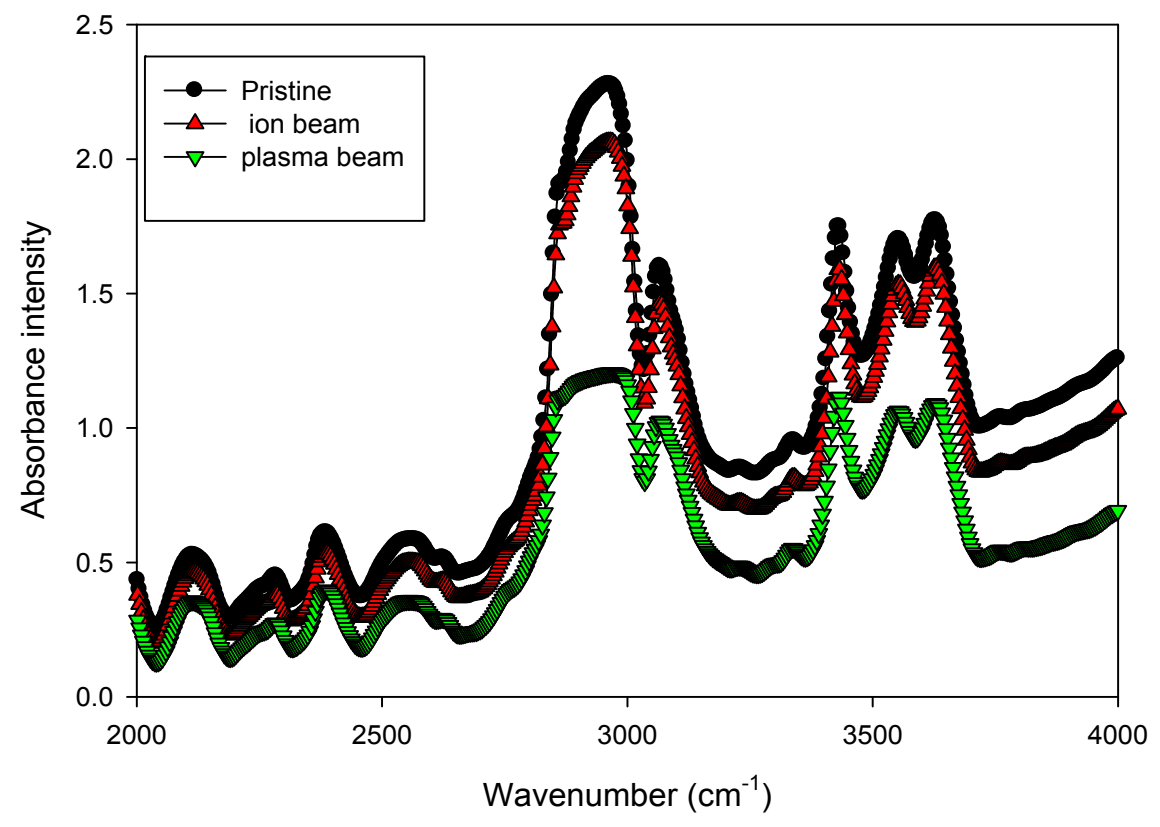

Figure 5. FTIR spectra of the pristine and irradiated PET films using Argon plasma and ion beams.

\section{Scanning electron microscopy (SEM)}

Polyethylene terephthalate (PET) film is transparent and the surface is smooth (Costa et al., 1997). The color of films gradually changes with irradiation from. The change in the color of polymer could be attributed to the formation of hydrogenous carbon clusters. The pristine sample showed rather relatively smooth surface as shown in Figure 6a. On the other hand, the SEM micrographs of irradiated samples by Argon ion beam display numerous small voids on the surface of the PET shown in Figure 6b. By using irradiated plasma, there was clear roughness on the surface of the irradiated samples and the resulting voids become large sized as 


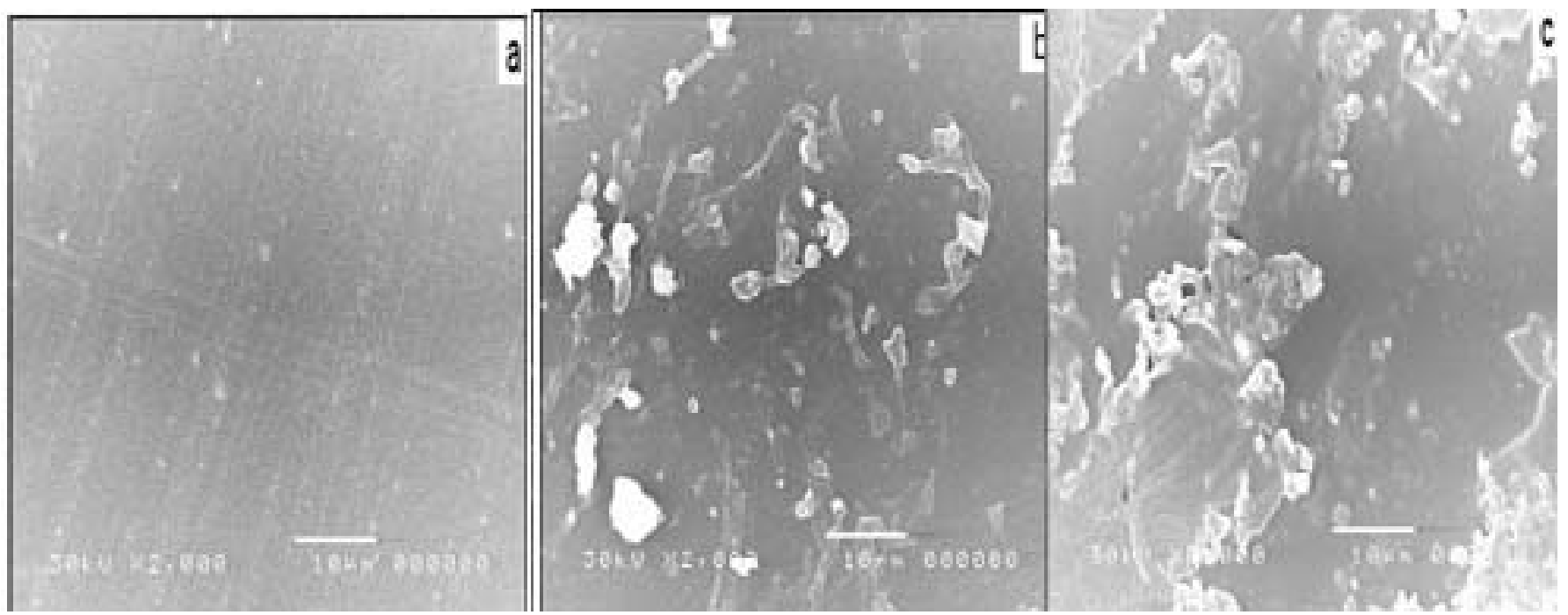

Figure 6. SEM micrographs for the pristine and irradiated PET by using Argon plasma and ion beams.

shown in Figure 6c. Bombardment of PET by Argon plasma is more efficient than Argon ion beam.

\section{Surface wettability}

Wettability and adhesion of polymers / films can be controlled by using surface modification techniques such as exposure to plasma, ion beams, flame, chemicals, enzymes etc. Wettability can also be regulated by changing chemical composition of the surface. In addition, surface roughness can be an important factor for enhancing the adhesion and wettability. Wettability is governed by molecular interaction of the outermost surface layer of a few angstrom units.

Contact angle is one from several independent methods that has been used to estimate solid surface tension (Liqing et al., 2009). Contact angle measurement is easily performed by establishing the tangent (angle) of a liquid drop with a solid surface.

$$
\frac{y_{l}(1+\cos \theta)}{2 \sqrt{y_{l}^{d}}}=\sqrt{y_{s}^{d}}+\sqrt{y_{s}^{p}} \cdot \sqrt{\frac{y_{l}^{p}}{y_{l}^{d}}}
$$

Equation 1 contains two unknowns' dispersive $\left(\gamma_{s}{ }^{d}\right)$ and polar $\left(\gamma_{s}{ }^{p}\right)$ surface energies of the solid (Soliman et al., 2013). To obtain these unknown parameters, one has to use contact angle measurements of at least two different liquids from Table 1.

The change in the contact angle on PET as a function of plasma expoure time and ion beam fluence are shown in Figure $7 a$ and $b$, respectively. It can be noted that as the exposure time increases, the contact angle decreases. The water contact angle decreases from 75 to $2.9^{\circ}$ in case of plasma and decreased to $44^{\circ}$ by using ion beam as shown in Table 2. The change of contact angles for the irradiated polymers is due to the formation of hydrophilic groups rather than the change of surface roughness. Hydrophilic group formation is composed of a two-step process. The first one is the creation of free radicals on a polymer surface by plasma irradiation. In the second step, interaction between free radicals in polymer chains and oxygen atoms results in the formation of polar groups such as carboxyl, carbonyl, hydroxyl and ester groups (Fernando et al., 2007). Thus, the decrease of the contact angle as a function of exposure time is due to the formation of new hydrophilic groups and the oxidized layer on the surface of polymer (Costa et al., 1998).

\section{Surface free energy}

The change in the surface free energy of PET as function of Argon plasma exposure time ( $\mathrm{min})$ and ion beam fluency were observed in Figure 8a, b, respectively. The surface free energy increased from 35 to 75 and 62.6 $\mathrm{mJ} / \mathrm{m}^{2}$ by using Argon plasma and Argon ion beam, respectively. Also, one notes that the irradiations effectively increase the polar component and the dispersive component as shown in Table 3 . Increasing the polar component in polymer is mainly due to the formation of polar and/or hydrophilic groups. From these results, the large decrease in contact angle can be attributed to the dominant increase of the polar component in the surface free energy of the modified polymers. 


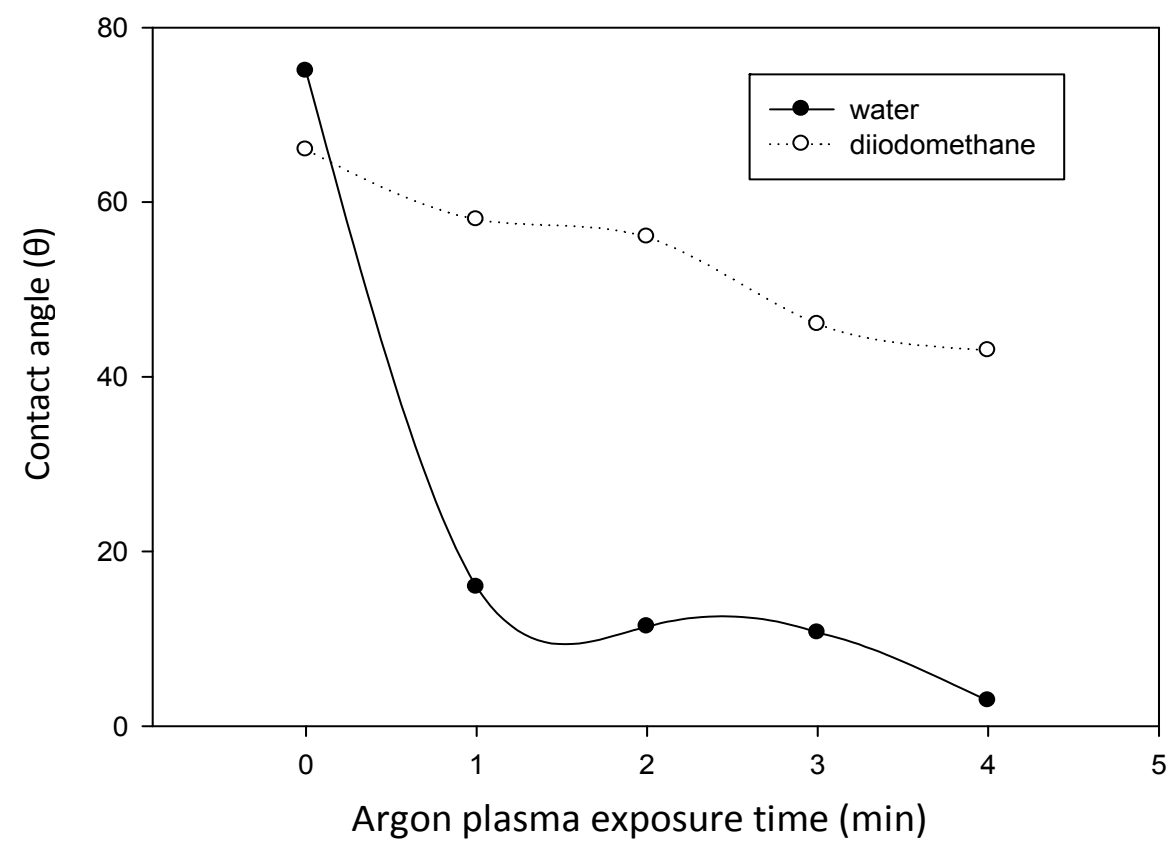

(a)

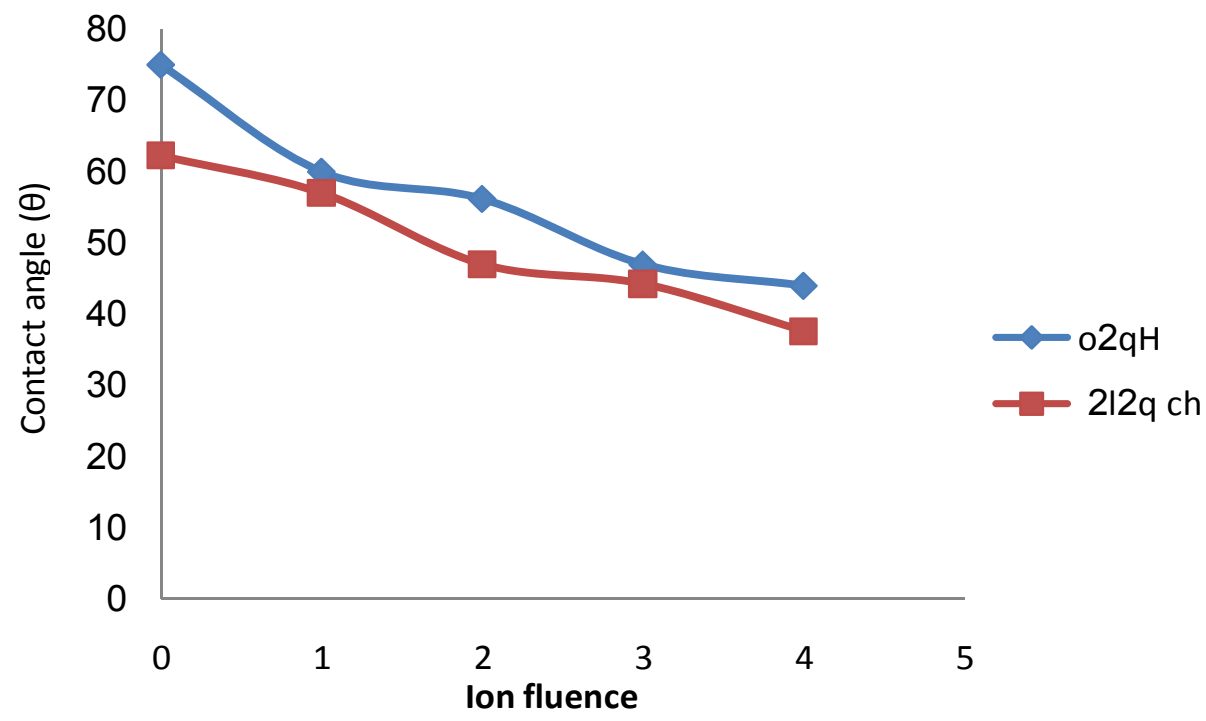

(b)

Figure 7. a) Change in the contact angle of PETas a function of Argon plasma exposure time; b) Change in the contact angle of PET as a function of Argon ion beam fluence.

\section{Conclusions}

In this work, it was concluded that, the characteristics of cold cathode ion source were studied with different operating parameters to get the optimum conditions for use in plasma and ion beam irradiation of some polymer materials. It could be found from this figure that, an increase of the discharge current was accompanied by an increase of the output ion beam current at magnetic field intensity of 180 gauss and Argon gas pressure, $P_{\mathrm{Ar}}$
$=2 \times 10^{-4}$ mbar. Such results showed that this cold cathode ion source is quite suitable for impact processes, as it gives high discharge and ion beam currents with a wide beam diameter up to $2.2 \mathrm{~cm}$. The effect of the Argon plasma and ion beam treatment on the surface properties of polyethylene terephtalate (PET) polymers was studied. The infrared absorption spectra of the PET substrates in a wave number range of 2000 to $4000 \mathrm{~cm}^{-1}$ reveal the presence of an absorbance band at about $2930 \mathrm{~cm}^{-1}$. The intensity of bands is more reduction in case of 

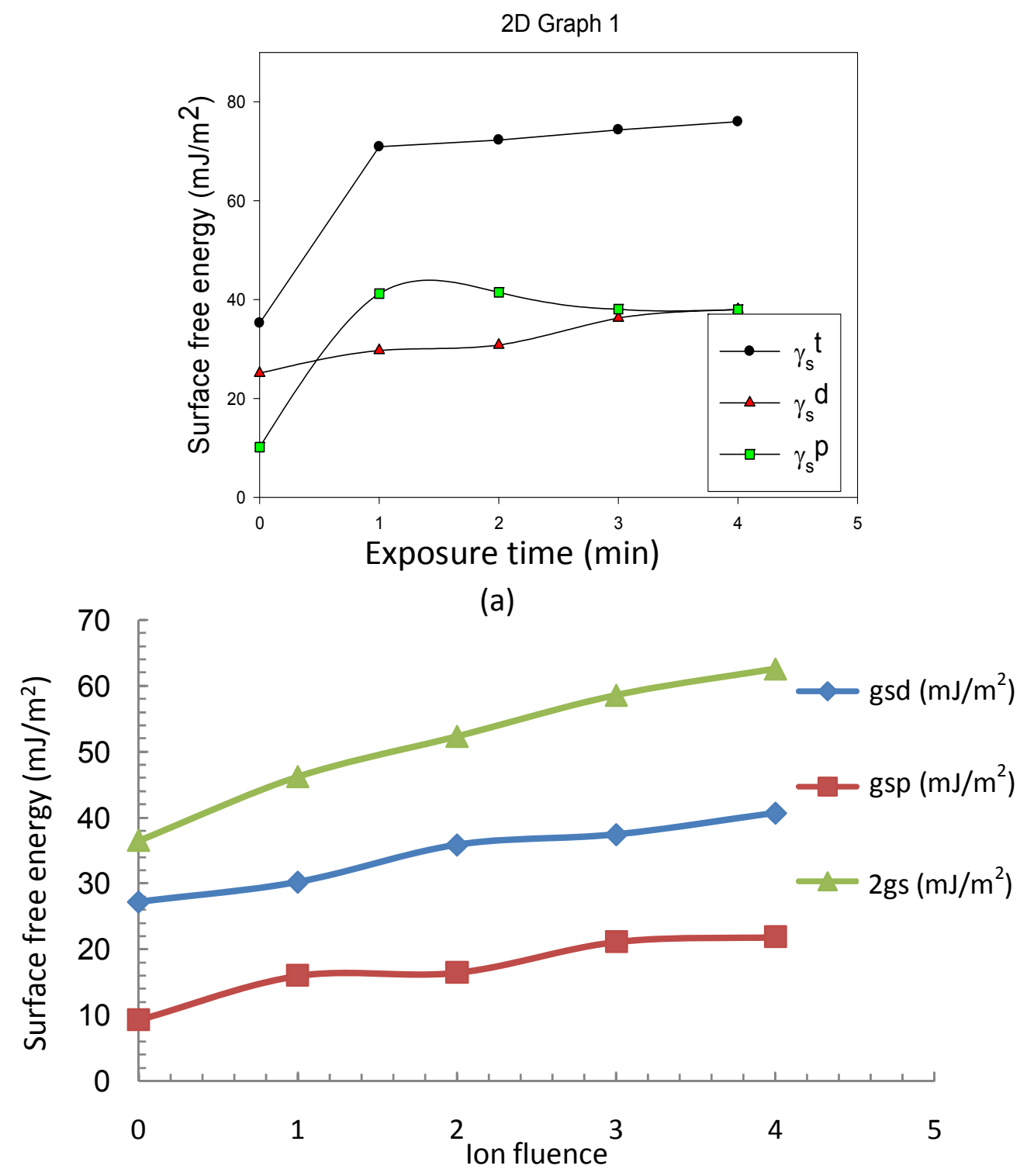

(b)

Figure 8. (a) Change in the surface free energy for PET as a function of Argon plasma exposure time; (b) Change in the surface free energy for PET as a function of Argon ion beam fluence.

Table 1. Surface free energy of the proposed liquids (Liqing et al., 2009).

\begin{tabular}{|c|c|c|c|}
\hline Liquid & Surface free energy $\mathrm{Y}_{1}(\mathrm{Nm})$ & Polar component $\mathrm{y}_{\mathrm{I}}^{\mathrm{p}}(\mathrm{Nm})$ & Dispersion component $\gamma_{1}^{d}(\mathrm{Nm})$ \\
\hline Water & 72.1 & 52.2 & 19.9 \\
\hline $\mathrm{Ch}_{2} \mathrm{I}_{2}$ & 50.8 & 0 & 50.8 \\
\hline
\end{tabular}

Argon plasma than Argon ion beam.

The SEM micrographs of irradiated samples by Argon ion beam display numerous small voids on the surface of the PET. By irradiated using plasma, the roughnesses clearly on the surface of the irradiated samples and the voids have large size. Bombardment of PET by Argon plasma is more efficient than Argon ion beam; the surface free energy increased from 35 to 75 and 62.6 $\mathrm{mJ} / \mathrm{m}^{2}$ by using Argon plasma and Argon ion beam, respectively. The large decrease in contact angle can be 
Table 2. The contact angles $(\theta)$ for PET surface as a function of plasma exposure time and ion beam fluence.

\begin{tabular}{cccccc}
\hline Exposure time (min.) & $\theta_{\mathrm{H} 20}$ & $\theta_{\text {ch212 }}$ & lon fluence & $\theta_{\mathrm{H} 20}$ & $\theta_{\text {ch212 }}$ \\
\hline Pristine & 75.00 & 66.00 & 0 & 75.00 & 66.00 \\
1 & 15.90 & 58.00 & $1 \times 10^{-18}$ & 60 & 57 \\
2 & 11.40 & 56.00 & $2 \times 10^{-18}$ & 56.5 & 47 \\
3 & 10.70 & 46.00 & $3 \times 10^{-18}$ & 47 & 44.25 \\
4 & 2.90 & 43.00 & $4 \times 10^{-18}$ & 44 & 37.625 \\
\hline
\end{tabular}

Table 3. The dispersive surface free energy $\left(\gamma_{\sigma}{ }^{\delta}\right)$ and the polar surface free energy $\left(\gamma_{\sigma}{ }^{\pi}\right)$ for PET surface as a function of plasma exposure time and ion beam fluency.

\begin{tabular}{|c|c|c|c|c|c|c|c|}
\hline $\begin{array}{l}\text { Exposure time } \\
\text { (min) }\end{array}$ & $\begin{array}{c}\gamma_{\sigma}^{\delta} \\
\left(\mathrm{mJ} / \mathrm{m}^{2}\right)\end{array}$ & $\begin{array}{c}\gamma_{\sigma}^{\pi} \\
\left(\mathrm{mJ} / \mathrm{m}^{2}\right)\end{array}$ & $\begin{array}{c}\gamma_{\sigma} \\
\left(\mathrm{mJ} / \mathrm{m}^{2}\right)\end{array}$ & $\begin{array}{c}\text { lon } \\
\text { fluence }\end{array}$ & $\begin{array}{c}\gamma_{\sigma}{ }^{\delta} \\
\left(\mathrm{mJ} / \mathrm{m}^{2}\right)\end{array}$ & $\begin{array}{c}\gamma_{\sigma}^{\pi} \\
\left(\mathrm{mJ} / \mathrm{m}^{2}\right)\end{array}$ & $\begin{array}{c}\gamma_{\sigma} \\
\left(\mathrm{mJ} / \mathrm{m}^{2}\right)\end{array}$ \\
\hline Pristine & 25.10 & 10.15 & 35.25 & 0 & 25.10 & 10.15 & 35.25 \\
\hline 1 & 29.70 & 41.22 & 70.92 & $1 \times 10^{-18}$ & 30.25 & 16 & 46.25 \\
\hline 2 & 30.80 & 41.47 & 72.28 & $2 \times 10^{-18}$ & 35.88 & 16.48 & 52.36 \\
\hline 3 & 36.26 & 38.07 & 74.33 & $3 \times 10^{-18}$ & 37.45 & 21.16 & 58.61 \\
\hline 4 & 38.01 & 37.97 & 75.98 & $4 \times 10^{-18}$ & 40.70 & 21.90 & 62.61 \\
\hline
\end{tabular}

attributed to the dominant increase of the polar component in the surface free energy of the modified polymers in Argon plasma than Argon ion beam.

\section{Conflict of Interests}

The author(s) have not declared any conflict of interests.

\section{REFERENCES}

AbdeIRahman MM, Helal A, Moustafa OA and Abdel Salam FW (2008). High efficiency glow discharge ion source. J. Nucl. Radiat. Phys. 3(1):1-9.

Chen JR (2001). Low-temperature Plasma Chemistry and Application, Science Press, Beijing p. 1.

Cho S, Han S, Kim KH, Beag YW, Koh SK (2003).Surface modification of polymers by ion-assisted reaction. Thin Solid Films. 445:332-341. http://dx.doi.org/10.1016/S0040-6090(03)01176-3

Chico B, Martinez L, Perez FJ (2005). Nitrogen ion implantation on stainless steel: AFM study of surface modification. Appl. Surf. Sci. 243(1-4):409-414. http://dx.doi.org/10.1016/j.apsusc.2004.09.097

Costa L, Luda MP, Trossarelli L, Brach del Prever EM, Crova M, Gallinaro P (1998). In vivo UHMWPE biodegradation of retrieved prosthesis. Biomater. 19(15):1371-85. http://dx.doi.org/10.1016/S0142-9612(98)00013-1

Drabika M, Kousala J, Pihosha Y, Choukourova A, Biedermana H, Slavinskaa D, Mackovac A, Boldyrevac A, Pesickad J (2007). Composite $\mathrm{SiOx} /$ hydrocarbon plasma polymer films prepared by $\mathrm{RF}$ magnetron sputtering of $\mathrm{SiO} 2$ and polyimide. Vacuum. 81(7):920927. http://dx.doi.org/10.1016/j.vacuum.2006.10.013

Ektessabi AM, Yamaguchi K (2000). XPS study of ion beam modified polyimide films. Thin Solid Films 377:621-625. http://dx.doi.org/10.1016/S0040-6090(00)01444-9

Fernando SS, Christensen PA, Egerton TA, White JR (2007). Carbon dioxide evolution and carbonyl group development during photodegradation of polyethylene and polypropylene. Polym. Degrad Stabil. 92(12):2163-2172.

http://dx.doi.org/10.1016/j.polymdegradstab.2007.01.032

Kotov DA (2004). Broad beam low-energy ion source for ion-beam assisted deposition and material processing. Rev. Sci. Instr. 75(5):1934-1936. http://dx.doi.org/10.1063/1.1702109

Liqing Ya, Jierong C, Yafei G, Zheng Z (2009). Surface modification of a biomedical polyethylene terephthalate (PET) by air plasma. Appl. Surf. Sci. 255(8):4446-4451.

http://dx.doi.org/10.1016/j.apsusc.2008.11.048

Reznickova A, Kolska Z, Hnatowicz V, Stopka P, Svorcik V (2011) Comparison of glow Argon plasma-induced surface changes of thermoplastic polymers. Nucl. Instrum. Methods B. 269(2):83-88. http://dx.doi.org/10.1016/j.nimb.2010.11.018

Pelagad SME, Singh NL, Qureshi A, Rane RS, Mukherjee S, Deshpande UP, Ganesan V, Shripathi T (2012). Investigation of surface properties of Ar-plasma treated polyethylene terephthalate (PET) films. Nucl. Instrum. Methods B. 289:34-38.

http://dx.doi.org/10.1016/j.nimb.2012.08.010

Soliman BA, Abdel Rahman MM and Abdelsalam FW (2013). Irradiation effect on PET surface using low energy Argon ion beam. J. Nucl. Mater. 432(1-3):444-449.

http://dx.doi.org/10.1016/j.jnucmat.2012.08.006

Zhiyong Z, Changlong L, Youmei S, Jie L, Yuhua T, Yucfan J, Junli D (2002). Modification of polyethylene terephthalate under high-energy heavy ion irradiation. Nucl. Instrum. Methods Phys. Res. B. 191(14):723-727. http://dx.doi.org/10.1016/S0168-583X(02)00641-9 